\title{
A Case Study in Loyalty and Satisfaction Research
}

\author{
K. Vanhoof, Josee Bloemer and K. Pauwels \\ Limburgs Universitair Centrum \\ Departement Bedrijfskunde \\ Universitaire Campus \\ B-3590 Diepenbeek \\ Belgium \\ Telephone : +31-11-268608 \\ Fax : $+31-11-268700$ \\ E-mail : vanhoof@rsftew.luc.ac.be
}

\begin{abstract}
Over the years, research in the field of the relationship between satisfaction and loyalty has been confronted with a number of conceptual, methodological, analytical as well as operational drawbacks. We introduce an analysis method, based on machine learning techniques. The method provides insight into the nature of the relationship between satisfaction and loyalty. In this article, building on previous research concerning brand and dealer loyalty, the relationship between satisfaction with the car, satisfaction with the dealer (sales and after-sales), brand loyalty and dealer loyalty (sales and after-sales) has been investigated. The method has been evaluated and the results are compared with the results of a frequently used method.
\end{abstract}

Keywords: loyalty and satisfaction research, relevance measure, classification rules 


\section{Introduction}

Over the years, research in the field of the relationship between satisfaction and loyalty has been confronted with a number of conceptual, methodological, analytical as well as operational drawbacks. This article will concentrate on the analytical difficulties.

First, most of the time, the distribution of satisfaction scores is rather skewed (Fornell, 1992; Reichheld, 1996). Many respondents indicate that they are 'very satisfied' or at least 'satisfied' and only a few indicate that they are 'not so satisfied' or 'not satisfied at all'. Second, the most widely used analyzing techniques assume linear relations between satisfaction and loyalty. However, there are indications that these types of relations may not be typical for this research domain. It has been suggested for instance that the relationship between low levels of satisfaction and loyalty may differ from the relationship between high levels of satisfaction and loyalty. Coyne (1989) hypothizes the existence of thresholds of satisfaction for affecting customer behavior. Heskett et al (1994) and Jones and Sasser (1995) argue that only extremely satisfied customers demonstrate loyal behavior.

This picture becomes even more complicated if not just one type of loyalty is taken into account but different types. For instance, brand loyalty and store loyalty or dealer loyalty. Studies generally indicate that store or dealer loyalty is an intervening variable between satisfaction with the product and brand loyalty, but the nature of the relationship remains unclear.

Concentrating on these analytical problems within the field of the relationship between customer satisfaction and loyalty, we introduce in this article a framework of analysis methods, which helps to resolve some of the above mentioned issues. In the framework no linear relationships are presumed and different relations between different factors are allowed for. Moreover, it allows to take into account the skewness of the original data-set. Last but not least, it also helps to provide insight into the nature of the relationship between satisfaction and loyalty. In this article, building on previous research concerning brand and dealer loyalty, the relationship between satisfaction with the car, satisfaction with the dealer (sales and after-sales), brand loyalty and dealer loyalty (sales and aftersales) will be investigated.

\section{Method of analysis}

The primary goal of the proposed method is the discovery, representation and analysis of 'interesting' data regularities and dependencies between attributes (such as satisfaction) and the concept or goal variable (such as loyalty). In this application interesting' means that we are able to confirm or reject hypotheses from previous research. More concrete, the following hypotheses are of special interest : 
A. the relationship between low levels of satisfaction and loyalty may differ from the relationship between high levels of satisfaction and loyalty;

B. the existence of thresholds of satisfaction;

C. only extremely satisfied customers demonstrate loyal behavior.

For reaching our goal we used from the machine learning community classsensitive discretization, a context-sensitive relevance measurement technique and the analysis of classification rules as research methods.

\subsection{Discretization}

When the discretization algorithm is concept-sensitive, it is possible to construct intervals of consecutive attribute values which feature a concept distribution that is uniform and homogeneous but, at the same time, contrasts the distributions of adjacent intervals significantly.

A top-down method for discretizing continuous attributes based on a minimal entropy heuristic, presented in Catlett (1991) and Fayyad \& Irani (1993), is also used in our experimental study. This supervised algorithm uses the concept information entropy of candidate partitions to select intervals for discretization. By using this concept sensitive discritesation algorithm, we are able to detect threshold values of satisfaction (hypotheses $B$ ).

For discretizing the concept (goal variable) we used the monothetic contrast criterion (Van de Merckt 1993):

$$
\operatorname{Contrast}\left(N_{1}, N_{2}, A\right)=\frac{N_{1} N_{2}}{N_{1}+N_{2}}\left(m_{1}-m_{2}\right)^{2}
$$

where $N_{1}, N_{2}$ are the number of cases of the resulting binary split and $m_{i}$ is the mean value for attribute $A$ of $N_{i}$ instances. The desirable split is the cut point that produces the highest contrast. As a stopping criterion we used the MDLP criterion.

\subsection{Contextual merit and determination of satisfiers, dissatisfiers and performers}

Contextual merits (Hong 1994, Vanhoof 1995) capture relative importance of attributes in distinguishing the concept values in the context of other attributes. Using this measure has one main advantage: we have one common selection criterium to determine the most interesting attributes in different contexts.

So it is possible to find the most important attributes, in the context of the other attributes, separately for every loyalty value. This allows us to define our definitions. An attribute is called a dissatisfier when it has a high contextual merit for a low loyalty level an a low contextual merit for a high loyalty level. An attribute is called a satisfier when it has a low contextual merit for a low 
loyalty level and a high contextual merit for a high loyalty level. An attribute is a performer when it has a high contentual merit for a low and high loyalty level. An attribute is a less-relevant attribute when it is nor a satisfier nor a dissatisfier nor a performer.

\subsection{Analysis of the corresponding classification rules}

The previous definitions(satisfiers, dissatisfiers,...) can be strengthened by analysing the most interesting corresponding classification rules. A corresponding rule is a rule where the level of the independent attribute is the same as the level of the concept. A confidence ar coverage level is considered as high when it is above $70 \%$. For a dissatisfier $\mathrm{A}$, the most interesting corresponding rule is 'IF satisfaction $=$ low Then loyalty $=$ low'. When this rule shows a high confidence and a low coverage level, this attribute is considered as a penalty attribute. For a satisfier the most interesting corresponding rule is 'IF satisfaction= high Then loyalty $=$ high'. When this rule shows a high confidence and a low coverage level, this attribute is considered as a reward attribute. When the confidence level is low and the coverage level is high, the attribute is a characteristic descriptor. When both confidence and coverage level are high, we may conclude that the attribute level and the concept level are strongly related.

For a performer $\mathrm{C}$, the most interesting corresponding rules are: 'IF satisfaction $=$ low Then loyalty $=$ low' and 'IF satisfaction $=$ high Then loyalty $=$ high'. Attribute $\mathrm{C}$ is called a basic attribute when the first rule indicates a penalty and the second rule a characteristic pattern. The attribute $\mathrm{C}$ is called an excitement attribute when the first rule shows a characteristic and the second rule a reward pattern. Finally, the combination of a penalty pattern and a reward pattern indicates a strongly related performer.

\section{Research design}

Since we choose the automobile market as the research setting, the concepts included in the analysis are: satisfaction with a car, satisfaction with the sales service, satisfaction with the after sale service, brand loyalty, dealer sales loyalty and dealer after-sales loyalty.

The respondents in the empirical part of the study are customers of different automobile dealers $(n=407)$ of two related German brands in the Netherlands. These two brands belong to the same holding and are therefore often sold by the same dealer. However, brand A is generally regarded as more exclusive and expensive than brand $\mathrm{B}$. The market shares of both brands differ remarkably; brand A has a smaller share than brand B. Because the respondents had to express their feelings about the sales service, the car had to be bought less than two years before. Furthermore, the customer had to have some experience with the after sales service, which leads us to impose a minimum of a one year ownership. Previous research (Bloemer and Lemmink, 1992) found significant differences 
with respect to loyalty between new and used cars and between automobiles for private and for business use. In order to avoid difficulties here and prevent them from confusing our findings, we decided to concentrate on new cars for private use. Therefore, a homogeneous group of car owners will be researched here.

\section{Results, discussion and managerial implications}

Overviewing our findings (table 1), the mutual dependence between the loyalty constructs becomes clear. Especially brand loyalty and dealer sales loyalty are closely linked. A second look at the results for each brand seperately, reveals important differences however. Table 1 summarizes the findings about the independent attributes and the loyalty concept (in bold) for both brands. The classifaction results (satisfier, dissatisfier,...) and the patterns of the corresponding classification rules, based on the contextual merit analyses, are shown in seperate columns.

Table 1: Summary of the general findings for brand A and brand B

\begin{tabular}{|c|c|c|c|c|}
\hline Brand Loyalty & Brand A & Role & Brand B & Role \\
\hline Dissatisfiers & Satisfaction Sales & $\mathrm{P}$ & 1 & \\
\hline Satisfiers & Dealer AS loyalty & $\mathrm{C}$ & Dealer AS loyalty & $\mathrm{R}$ \\
\hline Performers & Dealer S loyalty & E & Dealer S loyalty & SR \\
\hline less relevant & Satisfaction AS & & $\begin{array}{l}\text { Satisfaction AS } \\
\text { Satisfaction Sales }\end{array}$ & \\
\hline \multicolumn{5}{|c|}{ Dealer Sales Loyalty } \\
\hline Dissatisfiers & $\begin{array}{l}\text { Satisfaction Car } \\
\text { Satisfaction Sales } \\
\text { Satisfaction AS }\end{array}$ & \begin{tabular}{|c|}
$\mathrm{P}$ \\
$\mathrm{SR}$ \\
$\mathrm{P}$
\end{tabular} & Satisfaction Sales & $\mathrm{P}$ \\
\hline Satisfiers & 1 & & $T$ & \\
\hline Performers & $\begin{array}{l}\text { Brand loyalty } \\
\text { Dealer AS loyalty }\end{array}$ & \begin{tabular}{|l|}
$\mathrm{SR}$ \\
$\mathrm{SR}$
\end{tabular} & $\begin{array}{l}\text { Brand Loyalty } \\
\text { Dealer AS loyalty }\end{array}$ & $\begin{array}{l}\mathrm{B} \\
\mathrm{B}\end{array}$ \\
\hline less relevant & 1 & & $\begin{array}{l}\text { Satisfaction Car } \\
\text { Satisfaction AS }\end{array}$ & \\
\hline \multicolumn{5}{|c|}{ Dealer after-sales loyalty } \\
\hline Dissatisfiers & Satisfaction Sales & $\mathrm{P}$ & Satisfaction AS & $\mathrm{P}$ \\
\hline Satisfiers & 1 & & 1 & \\
\hline Performers & $\begin{array}{l}\text { Dealer S loyalty } \\
\text { Brand loyalty }\end{array}$ & B & $\begin{array}{l}\text { Dealer S loyalty } \\
\text { Brand loyality }\end{array}$ & $\begin{array}{l}\mathrm{B} \\
\mathrm{B}\end{array}$ \\
\hline less relevant & $\begin{array}{l}\text { Satisfaction Car } \\
\text { Satisfaction AS }\end{array}$ & & $\begin{array}{l}\text { Satisfaction Car } \\
\text { Satisfaction Sales }\end{array}$ & \\
\hline
\end{tabular}

Legend: $\mathrm{AS}=$ After Sales, $\mathrm{S}=$ Sales, $\mathrm{P}=$ Penalty; $\mathrm{C}=$ characteristic, $\mathrm{R}=\mathrm{Re}-$ ward, $\mathrm{SR}=$ strongly related, $\mathrm{B}=$ basic, $\mathrm{E}=$ exciter. 
In the case of the exclusive brand $A$, it is obvious that the satisfaction with the car must be high for brand loyalty to occur. Our findings confirm satisfaction with the car being a performer factor for brand loyalty. However, satisfaction with the car is neither the only nor the most important attribute for brand loyalty. The contextual merit of dealer sales loyalty is twice as high, indicating that customer who are loyal to the dealer, also demonstrate brand loyalty. Another attribute influenced by dealers, satisfaction with the sales service, is a penalty factor. A customer dissatisfied with the sales service is not likely to stay loyal to the brand. When the minimum requirements for brand loyalty are met, dealer after-sales loyalty starts to play a role. Customers who return to the same dealer for after-sales service are likely to buy the same kind of brand on the next purchase occasion.

For brand B, the direct impact of satisfaction on loyalty is more pronounced. First of all, satisfaction with the car is the only relevant satisfaction measure. Improving satisfaction with the car is likely to result in proportionately higher levels of brand loyalty (basic performer). Manufacturers and dealers should therefore focus on sound car quality, taking into account that brand B customers feel capable of judging the quality of the car, since they base their loyalty decision on this judgement.

Dealers interested in improving low dealer sales loyalty, should above all concentrate on its penalty attribute; satisfaction with the sales service. The findings for dealer after-sales loyalty mirror those for dealer sales loyalty. Satisfaction with the after-sales service is a penalty dissatisfier. In contrast to brand A customers, for which this attribute was less relevant, brand B customers base their loyalty decision on the quality of the after-sales service. An excellent technical staff that can also communicate on the level of the brand B customer, will help the dealer in improving satisfaction and enhancing after-sales loyalty. Dissatisfied customers will use alternative service options. Again, excellent technical expertise and customer satisfaction is only the first step. Brand loyalty and dealer sales loyalty are basic performers and should be monitored as well. Finally, high levels of dealer after-sales loyalty can not be garantueed. Building on previous discussion, a transactional approach to dealing with brand B customers could be the best alternative.

\section{Comparison of the used method with Two-Stage-Least-Squares analysis}

Comparing the 2SLS analysis with the machine learning method, we notice identical results concerning the existence of relationships. In the 2SLS analysis for both brands, all the hypotheses about the direct link between a satisfaction and the corresponding loyalty construct were confirmed. The only exception was the non-significance of the relation between satisfaction with the after-sales service and dealer after-sales loyalty for brand $\mathrm{A}$. These findings correspond to the re- 
sults of the presented analysis method: whereas the satisfaction measure always shows to be a relevant attribute for the corresponding loyalty factor, satisfaction with the after-sales service is a less relevant attribute for dealer after-sales loyalty. In other words, the existence of relationships is correctly identified by means of the analysis method.

\section{Conclusion}

We presented an analysis method customized for our application and showed that this method can be used as a complementar method for the frequently (in this application domain) used two-stage-least-square analysis method. The 2SLS-method assumes linear relationships and lacks the richness of attribute classification. For instance, satisfaction with the car has an impact on dealer sales loyalty for both brands (significant correlation in 2SLS), but there is no means of establishing whether this satisfaction influences mainly the lower or the upper scores of dealer sales loyalty. In contrast, the analysis method classifies satisfaction with the car as a dissatisfier for brand $\mathrm{A}$ and as a satisfier for brand B. On the other hand, the absence of significance tests is a disadvantage of this method compared to the 2SLS-analysis.

In the context of the identified mutual dependence between the loyalty constructs, neither 2SLS nor the presented method can identify the direction of the relationship. Nevertheless, the method does break down these relations in terms of satisfiers,dissatisfiers and performers, providing additional insight in the nature of the relationship. This allows us to confirm or reject hypotheses from literature. The generated output is more comprehensible than a 2SLS model, so it was relatively easy for the domain experts to extract managerial conclusions and to link the results with previous results.

We conclude that the proposed method offers several advantages satisfactionloyalty research. However, additional research is needed to address its weaknesses and explore its possibilities in other research settings.

\section{References}

1. Bloemer, J.M.M., Lemmink, J.G.A.M.: The importance of cuistomer satisfaction in explaining brand and dealer loyalty. Journal of Marketing Management 8 (1992) 351-364.

2. Coyne, Kevin P.: Beyond Service Fads: Meaningful Strategies for the Real World. Sloan Management Review (Summer) (1989) 69-76.

3. Catlett, J.: On changin continuous attributes into ordered discrete attributes. In: European working session on learning (1991).

4. Fayyad, U.M., Irani, K.B.: Multi-interval discretizatioin of continouos-valued attributes for classification learning. In: M. Kaufmann (ed.) Proccedings of the 13th Internaltional Joint Conference on Artificial Intelligence (1993) 1022-1027. 
5. Fornell, C.: A national customer satisfaction barometer: the Swedish experience. Journal of Marketing 56 (1992) 6-21.

6. Heskett, J., Jones, T., Lovemer, G., Sasser, W., Schlesinger, L.: Putting the ServiceProfit Chain to work. Harvard Business Review (March-April) (1994) 164-171.

7. Hong, S. J.: Use of contextual information for feature ranking and discretization. Technical report RC 19664, IBM Research Division (1994).

8. Jones, T.O., Sasser, W.E.: Why Satisfied Customers Defect. Harvard Business Review (November-December) (1995) 88-99.

9. Merkckt, T. van de: Desion trees in numerical attributes spaces. In: M. Kaufmann (ed.), Proceedings of the 13th International Joint Conference on Artificial Intelligence (1993) 1016-1021.

10. Reichheld F.: The Loyalty Effect. The Hidden Force Behind Growth, Profits, and Lasting Value. Bain Company Inc. Harvard Business School Press. Boston, Massachusetts (1996).

11. Vanhoof, K., Swinnen, G.: Comparing different measures of relevance. In: New techniques and technologies for statistics (Eurostat seminar) (1995) 520-533, Bonn. 